\title{
Ideologia Política Esquerda-Direita - Estudo Exploratório do Eleitorado Português
}

\author{
João Pedro Baptista \\ Universidade de Trás os Montes e Alto Douro - baptistajoa0902@gmail.com \\ Marlene Loureiro \\ Universidade de Trás os Montes e Alto Douro - mloureiro@utad.pt
}

\begin{abstract}
Sumário
Este artigo pretende averiguar de que forma a ciais, económicos e culturais dos cidadãos, de dicotomia Esquerda-Direita é um dos elemenforma a perceber a ideologia política de cada tos tidos em conta no eleitorado, procurando verificar qual a sua compreensão e o seu coinquirido. As conclusões demonstram que o eleitorado inquirido apresenta dificuldades em nhecimento acerca desta díade política. Para isso, recorremos a um inquérito por questiocompreender, em se orientar e se autoposicionar na escala política Esquerda-Direita.
\end{abstract}

nário direcionado para avaliar os valores so-

Palavras-Chave: Esquerda, Direita, autocolocação, dicotomia política.

\section{Left-Right Political Ideology - Exploratory Study of the Portuguese Electorate}

\begin{abstract}
This article aims to find out how the Left-Right values of citizens, in order to understand the political dichotomy is present in the electorate, seeking to ascertain their understanding political ideology of each respondent. The conclusions show that the surveyed electorand knowledge about this political dyad. For this, we used a questionnaire survey aimed at assessing the social, economic and cultural ate presents difficulties in understanding, orienting and self-positioning on the left-right political scale.
\end{abstract}

Keywords: Left, Right, self-placement, political dichotomy. 


\section{INTRODUÇÃO}

Passados mais de três séculos da Revolução Francesa, a díade política Esquerda-Direita continua, diariamente, a servir de instrumento linguístico entre os agentes políticos, os eleitores e a comunicação social, quer a nível nacional quer internacional. Esta dicotomia política desempenha um papel fundamental não apenas no plano político, mas também no plano da linguagem. Os termos Esquerda e Direita tornaram-se, pois, instrumentos linguísticos de compreensão e orientação essenciais para que o cidadão consiga quer adotar uma posição ideológica com base nas crenças e valores que ocupa cada campo político, quer desmistificar os assuntos de carácter mais complexo atinente ao universo político.

Desta forma, esta dicotomia política continua a ser reconhecida pela imensa maioria dos cidadãos e a apresentar respostas perante as transformações sociais, culturais e económicas, assentes nas quais, as sociedades, maioritariamente as ocidentais, têm vivido. Importa, assim, referir que os significados atinentes a cada campo político têm sido alvo de diversas mutações e/ou adaptações à nova sociedade industrial avançada (Flanagan, 1987; Inglehart, 1971; Kitschelt \& Hellemans, 1990), daí a postura ideológica dos partidos, quer de Esquerda quer de Direita, ter vindo a ser moldada. Contudo, são diversos os autores (por exemplo, Converse, 2006; Fuchs \& Klingemann, 1990; Jacoby, 1991) que defendem a falta, por parte do eleitorado, não de conhecimento do espectro político Esquerda-Direita, mas, sobretudo, de compreensão dos diversos campos políticos que compõem esta dimensão. Ao passo que outros (por exemplo, Freire, 2006b; Knutsen, 1998), sem refutar essa ideia, acreditam também que o eleitorado se autocoloca na escala política Esquerda-Direita, sobretudo sobre a influência da sua identidade partidária.

Sendo assim, importa, portanto, questionarmo-nos sobre a capacidade do eleitorado em compreender, reconhecer e se autocolocar nos diversos campos políticos atinentes à escala política Esquerda-Direita. Será que o eleitorado se autoposiciona, nesta escala, aquando questionado sobre a sua autoperceção ideológica, de acordo com a sua identidade partidária e decisão eleitoral?

De forma a respondermos às questões acima expostas, a nossa investigação assenta sobre diversos objetivos específicos. Primeiro, pretende-se avaliar a capacidade do eleitorado do concelho de Vila Real em se orientar e autoposicionar na escala política Esquerda-Direita. Segundo, verificar se as ideologias políticas do eleitorado do concelho de Vila Real coincidem com o partido no qual votariam se houvesse eleições. 
Terceiro, pretende-se analisar o conhecimento dos inquiridos sobre a díade político-ideológica de Esquerda-Direita. E, em quarto lugar, sendo o concelho de Vila Real um concelho manifestamente de Direita, a julgar pelos resultados eleitorais ao longo de toda a democracia (vide: http://eleicoes.cne.pt), esta investigação procura averiguar se a autoperceção ideológica da amostra se posiciona também maioritariamente à Direita na Escala Política Esquerda-Direita (0-10).

A fim de atingirmos os objetivos a que nos propomos, a investigação compreende, primeiramente, uma abordagem teórica no que respeita, essencialmente, à díade política Esquerda-Direita relativamente à sua evolução e significado. De seguida, procederemos a uma análise minuciosa da literatura no atinente à orientação ideológica dentro desta dimensão política e, por conseguinte, aos valores e clivagens, às quais tem sido associada. Posteriormente, o nosso estudo compreenderá a análise e discussão dos resultados obtidos.

\section{RAZÃO DE DISTINÇÃO DAS POLÍTICAS DE ESQUERDA DAS DE DIREITA}

As ideologias políticas Esquerda e Direita, à semelhança de outras ideologias, apresentam a sua história e, consequentemente, a sua evolução. Ambas as "famílias de significados"1 (Wittgenstein, 2010), que as constituem, têm sido, ao longo dos anos, alvo de alterações, variações ou mutações, intimamente, relacionadas com questões de natureza social, económica e cultural das várias gerações, pelo que o que se identifica atualmente como sendo de Esquerda, pode estar na iminência de passar a estar, futuramente, associado a uma política de Direita ou vice-versa (Huber \& Inglehart, 1995; Laponce, 1981).

Esta díade política ficou, logo após o seu surgimento, delineada por um lado, por uma Esquerda que se identificava como libertadora, a favor dos ideais republicanos e de um mercado livre, comum aos liberais da época e, por outro lado, por uma Direita conservadora relacionada com a manutenção da ordem, da regulação dos mercados, e que se revelava, essencialmente, como sendo tradicionalista e aliada à religião e/ou à Igreja (Eatwell, 1992). Já a Esquerda defende a sobreposição da razão à religião, o que leva Edmund Burke a referir-se, àqueles que estavam a favor da Revolução Fran-

1 Para se obter o significado de uma determinada palavra deve-se, segundo o filósofo Ludwig Wittgenstein, ter em consideração uma "família de significados", pelo facto de não existir um sistema conceptual inteiramente estabelecido e rigorosamente estável. 
cesa, como sendo ateístas (Burke, 1982). No entanto, como salientamos anteriormente, o significado atinente ao campo político ora de Esquerda ora de Direita resulta dos diversos contextos relativamente a cada época.

Nesse sentido, importa debruçarmo-nos sobre o estudo de diversos autores (por exemplo, Bobbio, 1995; Bresser-Pereira, 1997; Pinto, 1996) que se preocuparam, num passado recente, em estabelecer uma razão de distinção, destes dois termos, bem diferente daquela associada à Revolução Francesa. Bobbio (1995) revelou-se, sem margens para dúvidas, o politólogo que melhor definiu um critério universal na distinção destas ideologias. De acordo com Bobbio (1995) a distinção das políticas de Esquerda e de Direita assenta, sobretudo, sobre a forma de se encarar e/ou interpretar o valor de igualdade, sobre o qual, o autor considera a Esquerda como sendo mais igualitária do que a Direita. A Esquerda prioriza, assim, a igualdade e a justiça social, encarando sempre como possível a eliminação de todas as desigualdades sociais, revelando-se otimista na procura de um mundo mais igualitário. Já a Direita interpreta as desigualdades sociais como algo que se revela necessário e benéfico para a sociedade. No entanto, ambas defendem, naturalmente, a igualdade, mas nem a Esquerda a defende radicalmente, nem a Direita a rejeita extremamente (Bobbio, 1995; Lukes, 2003; Rosas \& Ferreira, 2013).

Já para delinear os vários campos políticos atinentes ao espectro político Esquerda-Direita, Bobbio (1995, pp. 118-119) recorre à dimensão «liberdade versus autoridade», na qual distinguimos uma Extrema-Esquerda igualitária e autoritária, como exemplo os Jacobinos; um Centro-Esquerda que define como sendo simultaneamente igualitário e libertário, estando associado à ala Social-Democrata; um Centro-Direita libertário e inigualitário que respeita a igualdade dentro do que é sobretudo estipulado pela lei, e uma Extrema-Direita antiliberal e anti-igualitária, relacionada com a dos governos ditatoriais.

No entanto, Bresser-Pereira (1997) acusa a análise de Bobbio (1995) como não sendo neutra, uma vez que acaba por admitir que se identifica como sendo de Esquerda. Para Bresser-Pereira (1997), Bobbio (1995) tende a fazer uma análise pejorativa da Direita, o que o leva a apresentar a sua própria análise que, embora distinta de Bobbio (1995), partilha da mesma linha de pensamento. Bresser-Pereira (1997) defende que a diferença está patente em "arriscar" ou não a ordem. Segundo o autor, é de Esquerda quem não receia "arriscar" ou alterar a ordem em função da justiça social, e identificam-se como sendo de Direita aqueles que pretendem antes manter ou conservar a ordem. Contudo, não quer dizer que não valorizem ambos a igualdade 
e a ordem, dado que " $[\mathrm{t}$ ]odos desejam a ordem, a segurança, a estabilidade, e todos também querem a justiça, a equidade, senão a igualdade pelo menos a igualdade de oportunidade" (Bresser-Pereira, 1997, p. 55).

No que respeita aos valores socioeconómicos que definem a sociedade, a Esquerda é, portanto, mais a favor de um mercado regulado e, por conseguinte, de uma maior intervenção do Estado na economia. Ao passo que a Direita se encontra relacionada com uma maior liberalização do mercado, a favor de uma menor importância do papel do Estado na economia, revelando-se mais a favor da desregulação dos mercados e da privatização dos serviços do que a Esquerda, que opta pela regulação e pelas nacionalizações (Luke, 2003).

Importa ainda salientar que a Esquerda se encontra aliada à mudança ou à alternativa, demonstrando um certo "otimismo antropológico" em criar novas realidades, arriscando assim a ordem social, ao passo que a Direita se revela a favor do status quo, com um "pessimismo antropológico" associado, mais tradicionalista e conservadora no atinente à mudança (Bobbio, 1995; Currito, 2012; Jost et al., 2009; Pinto, 1996).

\section{ORIENTAÇÃO IDEOLÓGICA DENTRO DO ESPECTRO POLÍTICO ESQUERDA-DIREITA}

Apesar das críticas, que têm sido apresentadas por diversos autores, ao longo das últimas décadas, à ideologia, como as teses do "fim da ideologia" (Aron, 1980; Bell, 2015; Lipset, 1987), o "fim da história" (Fukuyama, 1989) e a alegada superação da díade política Esquerda e Direita (Giddens, 1995), os termos Esquerda e Direita continuam a ocupar o quotidiano político da maioria das democracias ocidentais (Duarte, 2016; Gall \& Magni-Berton, 2013; Guedes, 2012; Inglehart \& Klingemann, 1976).

Estes termos assumem um papel, dentro do espectro político, para os cidadãos bastante semelhante ao dos pontos cardeais na leitura geográfica de um mapa. Ambos foram designados de forma atribuir um sentido de orientação ao cidadão, embora em contextos distintos, pois faz parte da natureza do ser humano, enquanto ser racional, estabelecer formas eficientes de ordenar e de interpretar toda a informação que o rodeia (Tavares, 2015).

Existem dicotomias em todo o campo do saber, desde a sociologia, a filosofia, a economia ou a política. As dicotomias, independentemente, do contexto a que dizem respeito, dividem, a julgar pela própria etimologia, duas partes antagónicas, que se 
anulam uma à outra, permitindo dividir o mundo em dois campos reciprocamente excludentes e exaustivos. Os significados atinentes a cada campo devem ser limitados e claros, o que impossibilita o encaixe, de qualquer movimento ou pensamento no campo da Esquerda ou da Direita ao mesmo tempo. Embora existam díades que se complementam, esta dicotomia política assume a Esquerda e a Direita como termos antitéticos (Bobbio, 1995; Correia, 2012).

Ainda que alguns autores tivessem achado que a maioria dos cidadãos se autoposicionam ou se autoidentificam com esta dicotomia sem terem um conhecimento ideológico do que a separa e/ou identifica (Converse, 2006; Jacoby, 1991), limitando-a apenas às elites políticas, esta terminologia permite, atualmente, não apenas aos atores políticos, mas a todos os abrangidos pela dimensão política - os eleitores e a comunicação social - obterem um sentido de orientação, na posição que devem tomar, relativamente aos assuntos atinentes à esfera política, servindo como um "código comunicacional" no sentido interpretativo entre ambas as partes, reduzindo assim, em grande parte, a complexidade do sistema político (Bobbio, 1995; Dalton, 2010; Freire, 2005; Fuchs \& Klingemann, 1990; Knutsen, 1995). O esquema politico horizontal Esquerda-Direita é reconhecido pela maioria dos cidadãos, os quais se posicionam com naturalidade num dos dois campos (Freire, 2006b; Heywood, 2003; Kroh, 2005; Lachat, 2015), o que justifica, de certo modo, a abundância de estudos, nos últimos anos, no campo da sociologia e da ciência política, sobre o comportamento eleitoral dos cidadãos, da evolução ideológica dos partidos e da competição partidária em torno desta dimensão política (por exemplo, Belchior, 2008; Freire, 2005; Guedes, 2012; Lisi, 2010; Weber, 2012).

Esta díade política tornou-se para a sociedade ocidental uma metáfora espacial horizontal que permite ao cidadão optar por uma determinada posição ideológica, assente na validação de diferentes ideais, opiniões ou crenças, impondo-se à verticalidade ou à distribuição de classes hierárquica que vigorou até à Revolução Francesa (Bobbio, 1995; Laponce, 1981; Lukes, 2003). Esta horizontalidade foi um dos fatores que mais justificou o facto de se ter tornado um instrumento de comunicação política generalizado pelas democracias ocidentais (Fuchs \& Klingemann, 1990).

De acordo com vários autores, os cidadãos posicionam-se no esquema político Esquerda-Direita pela forma como estão inseridos na sociedade, ou seja, de acordo com a componente social que os identifica, como por exemplo as pessoas que apresentam fortes laços para com os sindicatos, tendem a se autocolocar na Esquerda; pela sua fidelidade partidária e pela forma como se relacionam com os conflitos que definem 
a atualidade política, quer estejam eles relacionados com valores socioeconómicos, religiosos ou com as novas clivagens atinentes à "nova política" (Freire, 2006a; Fuchs \& Klingemann, 1990; Inglehart \& Klingemann, 1976; Knutsen, 1995).

No entanto, importa salientar que os significados, atinentes a cada um dos campos deste esquema, sofreram, ao longo dos anos, determinadas transformações ou evoluções ideológicas entre cada campo devido às influências externas socioeconómicas quer da postura das próprias instituições quer dos partidos políticos (ver Flanagan, 1987; Freire, 2009; Kitschelt \& Hellemans, 1990). A partir dos anos 1960, a sociedade adquire uma forma de encarar o mundo, mais plural, assente noutros ideais e preocupações que não tinham lugar anteriormente, o que gerou novos valores e novas crenças, implicando o surgimento de uma "nova política", intimamente relacionada com a transição dos valores materialistas (sociedade moderna) para os valores pós-materialistas (sociedade pós-moderna) (Flanagan, 1987; Flanagan \& Lee, 2003; Inglehart, 1971).

A "nova política" encontra-se relacionada com o despoletar de novos partidos políticos (verdes ou ecologistas, outros) que - com a defesa de novos valores não-económicos, assentes na proteção do ambiente, na igualdade e participação do cidadão na opinião pública, nos direitos das mulheres e dos homossexuais, entre outros - implicaram a reorientação ideológica da velha Esquerda e da velha Direita (Inglehart, 1990; Inglehart, 1997; Knutsen, 1995).

Desta feita, a denominada Nova Esquerda inclui temas relacionados com a liberdade e a autonomia pessoal e política; preocupações ambientais; pensamentos pluralistas quanto às opiniões e às ideias de vida ou questões relacionadas pela obtenção de uma melhor qualidade de vida (Achterberg, 2006; Flanagan, 1987, p. 1304; Inglehart, 1990; Inglehart, 1997; Kitschelt, 1988).

Os novos partidos políticos, associados à Esquerda do esquema político, estão relacionados com o crescimento de novos movimentos sociais libertários como os movimentos de paz, pelos direitos das mulheres na opção do aborto, pelos direitos de homossexuais e lésbicas, dos imigrantes, do cidadão na esfera pública e política, entre outros (Heywood, 2003; Inglehart, 1997).

Já a Nova Direita assume uma orientação "autoritária” (Flanagan, 1987) face à orientação "libertária" da Nova Esquerda, defendendo valores distintos como a disciplina, a autoridade e a ordem social e política, os costumes religiosos e tradicionais. Esta Direita surge como manifestação à Nova Esquerda, aquando as suas crenças estão a ser colocadas em causa (Inglehart, 1997) e difere da Direita tradicional no que 
respeita, essencialmente, à situação socioeconómica dos seus apoiantes (Freire, 2009; Ignazi, 1992). Ao passo que a Direita tradicional representava as classes sociais altas, nas quais predominava o capital e as preferências religiosas, a Nova Direita "apresenta um eleitorado [...] captado entre a pequena burguesia tradicional e entre as franjas mais inseguras e xenófobas do operariado bem como entre as camadas sociais com menor integração religiosa" (Freire, 2009, p. 266).

No entanto, voltando ao espectro político Esquerda-Direita, enquanto metáfora espacial, importa salientar que este esquema linear horizontal, unidimensional, que temos vindo a tratar, tem sido, pela comunidade académica, alvo de algumas contestações no sentido de ser insuficiente para considerar os significados de todas as ideologias (Albright, 2010; Heywood, 2003; Lachat, 2015; Rosas \& Ferreira, 2013; Tavares, 2015; Weisberg, 1974). O esquema político Esquerda-Direita deve ser definido a partir de uma mescla de significados e símbolos concretos e precisos, ao qual se torna impossível referir-se a todos os conflitos existentes, pelo que os significados devem ser atribuídos corretamente a cada campo do esquema de forma a definir cada símbolo ou significado como pertencente somente à Esquerda ou à Direita (Fuchs \& Klingemann, 1990).

O que define, de facto, a díade política Esquerda-Direita são os conflitos de natureza económica e sociocultural, que opõe, maioritariamente, o Estado ao Mercado. De acordo com Lachat (2015) não faz mais sentido a Esquerda e a Direita estarem situadas num esquema linear, exigindo por isso, pelo menos, mais uma dimensão a fim de acertar a posição de determinadas ideologias e questões especificas. Para Lachat (2015) o facto de este esquema ser delineado por duas dimensões, uma dimensão cultural e outra económica, faz com que seja necessário transformar a linha reta do esquema numa curva. Para o autor, os assuntos que separam os partidos de Esquerda não são os mesmos que separam os partidos de Direita. A Extrema-Esquerda assume-se muito mais igualitária e intervencionista que os partidos liberais de Esquerda, enquanto que na Direita as diferenças são mais salientes no que trata aos assuntos socioculturais que propriamente económicos, uma vez que todos eles defendem um Mercado livre.

Partilhando do mesmo pensamento, Heywood (2003) refere que a Esquerda e a Direita se encontram delineados por questões relacionadas com a igualdade e com o que diz respeito à expansão do Estado de bem-estar. Sendo a Esquerda mais igualitária e a Direita mais libertária. Mas o que o leva a defender um espectro não-linear são as semelhanças políticas que aproximam a Extrema-Esquerda da Extrema-Direita 
ou vice-versa. Atendendo às suas ideologias, quer o Comunismo quer o Fascismo assumiram políticas, extremamente, semelhantes, no sentido de se terem revelado, em tempos, como regimes ditatoriais e/ou autoritários.

Numa visão muito semelhante à dos autores acima citados (Heywood, 2003; Lachat, 2015), Tavares (2015), de forma a melhorar o espectro político, acrescenta, à semelhança de Eysenck (1964, pp. 280-281) o eixo Autoritário-Libertário perpendicular ao eixo Esquerda-Direita, atribuindo ao esquema a leitura de quatro quadrantes (Esquerda Libertária - Direita Libertária; Esquerda Autoritária - Direita Autoritária).

No entanto, no final do século XX, com a Queda do Muro de Berlim, a sociedade rendeu-se a um mundo globalizado, multicultural, regido por um sistema económico liberal e/ou capitalista, desencadeando os novos movimentos ideológicos, já anteriormente mencionados (Ball, Dagger, \& O’Neill, 2014). O que coloca em causa a validade do espetro político bidimensional, acima referenciado, pois, segundo Tavares (2015, p. 99), “este esquema não é suficiente para cobrir as várias possibilidades de posicionamento na crise do novo milénio» sendo por isso «necessário acrescentar uma terceira dimensão [...] um cubo". Deste modo, Tavares (2015) soma às dimensões Esquerda-Direita e Libertário- Autoritário, a dimensão Cosmopolita (Internacionalista, Federalista, Universalista) - Localista (Nacionalista/ Comunitária/Nativista), em que se opõe a Esquerda Libertária Cosmopolita à Direita Autoritária Localista.

\section{METODOLOGIA}

Após uma análise minuciosa da literatura, verificámos que a aplicação da Escala Política Esquerda-Direita, (usada, por exemplo por Budge \& Klingemann, 2001; Freire, 2006b; Guedes, 2012; Huber \& Inglehart, 1995), tem-se revelado fundamental para o suporte de diversas investigações no âmbito do estudo da orientação ideológico-partidária dos eleitores, do seu comportamento eleitoral e da análise dos diversos programas eleitorais dos partidos, sendo por isso a base da nossa investigação. A partir desta Escala Política Esquerda-Direita, alguns desses estudos procuram compreender as orientações ideológicas dos partidos e dos eleitores através da atribuição de diversas posições, distribuídas ao longo do esquema Esquerda-Direita, que representam campos ideológicos que classificam a sua ideologia ou orientação política.

Sendo assim, como método de investigação, recorremos à aplicação de um inquérito por questionário a uma amostra por conveniência, elaborado a partir da base de 
dados European Values Study (EVS). Este estudo (EVS 2008) dá continuidade a uma série de inquéritos (EVS 1981, 1990, 1999), realizados de 10 em 10 anos em vários países em simultâneo, nos quais Portugal tem participado desde 1990. O inquérito apresenta uma ampla gama de valores e indicadores que são relevantes para a diferenciação de Esquerda e Direita, pelo que as questões foram redimensionadas num conjunto de sistemas de valores cruciais para delinear os eixos principais atinentes ao posicionamento ideológico considerado. Com base na literatura existente, este questionário permitiu-nos fazer uma análise entre os valores modernos e pós-modernos, materialistas e pós-materialistas, bem como uma distinção entre orientações libertárias e autoritárias, enquadradas na questão denominada por "nova política" (Huber 1989; Inglehart \& Klingemann 1976; Knutsen, 1995). Por outro lado, as questões do inquérito estão relacionadas com os valores socioeconómicos, morais e religiosos, bem como com valores associados à "nova política" (Flanagan \& Lee, 2003). Neste inquérito são várias as clivagens indicadas: Estado-Igreja, Capital-Trabalho, Nova Política. Estas questões encontram-se, estrategicamente, enquadradas na Escala Política Esquerda-Direita de 10 pontos, em que a Esquerda compreende os pontos de 1 a 4, o Centro-Esquerda a posição 5, o Centro-Direita a posição 6, e a Direita de 7 a 10.

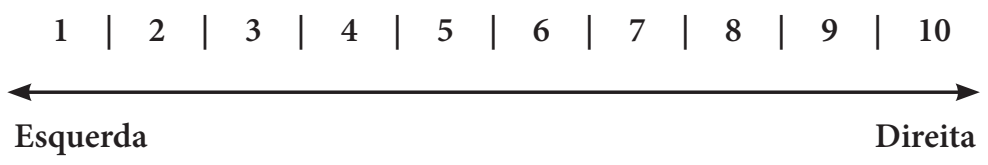

Figura 1. Escala Política Esquerda-Direita.

De forma a elaborarmos um diagnóstico preciso de cada inquirido, dentro da dimensão Esquerda-Direita, os inquiridos foram indagados no âmbito dos valores religiosos e morais, sobre qual a posição que Deus ocupa na sua vida, num determinado grau de importância (1 - nada importante; 10 - muito importante) e qual a opinião do inquirido relativamente ao aborto, em que se questiona se aprova ou desaprova numa situação em que a mulher não é casada, ou numa situação quando o casal não deseja ter filhos. Ainda dentro deste sistema de valores, no atinente a assuntos de moral, procuramos saber qual a opinião em relação à eutanásia, à pena de morte, à homossexualidade, à prostituição, ao uso legal de drogas e à inseminação artificial (1 - sempre; 10 - nunca). Em termos socioeconómicos, os inquiridos foram confrontados com questões relativas à sua posição perante a intervenção do Estado (1 - O 
Estado deve ser o principal responsável em assegurar a sobrevivência de todos; 10 As pessoas devem ser as principais responsáveis por assegurar a sua sobrevivência), procurando saber qual a sua posição relativamente à economia (1 - O Estado devia controlar as empresas; 10 - O Estado devia dar mais liberdade de ação às empresas), (1 - A propriedade do Estado na indústria e nos negócios devia aumentar; 10 - A propriedade privada na indústria e nos negócios devia aumentar), (1 - Os salários deveriam ser quanto possíveis iguais; 10 - Deveria haver incentivos para repensar o esforço individual); à confrontação de conflitos como: igualdade versus liberdade ( 1 - Acho que a liberdade e a igualdade são importantes. Mas se tivesse de escolher entre as duas, escolheria a igualdade, ou seja, que ninguém seja desfavorecido e que as diferenças entre as classes sociais não sejam tão acentuadas; 2 - Acho que a liberdade e a igualdade são importantes. Mas se tivesse de escolher entre as duas, escolheria a liberdade, ou seja, cada um poder viver em liberdade e desenvolver-se à vontade); libertário versus autoritário; mercado regulado versus mercado desregulado; alteração/ mudança versus ordem/status quo; bem como ainda a sua posição sobre a unificação da União Europeia e o patriotismo (Currito, 2012; Pinto, 1996; Zartaloudis, 2014).

Já relativamente aos aspetos sociais e raciais, o questionário permitiu que os inquiridos expressassem a sua opinião acerca da imigração, se os imigrantes colocam ou não os postos de trabalho em risco dos países para onde vão ( 1 - Os imigrantes não tiram postos de trabalho das pessoas dos países para onde vão; 10 - Os imigrantes tiram postos de trabalho das pessoas dos países para onde vão), ou se os costumes e tradições desses países acabam por se perder ( 1 - Os imigrantes não empobrecem a vida cultural do país para onde vão; 10 - Os imigrantes empobrecem a vida cultural do país para onde vão), (1 - É melhor, para o bem da sociedade, que os imigrantes mantenham os seus costumes e tradições; 10 - É melhor, para o bem da sociedade, que os imigrantes não mantenham os seus costumes e tradições, mas que adotem os costumes do país).

$\mathrm{O}$ inquérito, por questionário, foi aplicado a uma amostra por conveniência, através das redes sociais e através do denominado "porta-a-porta", de forma a evitar discriminar a faixa etária mais idosa da comunidade, que apresenta menos adesão do que os jovens às redes sociais. Optámos por utilizar um inquérito constituído, na maioria, por respostas fechadas (dicotomia Sim/Não; escolha múltipla; classificação por escalas) de forma a facilitar a análise quantitativa, qualitativa e comparativa dos resultados.

Por conseguinte, este estudo assume-se como uma investigação exploratória da posição ideológica dos eleitores do concelho de Vila Real, através da aplicação de 
inquérito, a uma amostra (200 cidadãos com idade igual ou superior a dezoito anos) por conveniência, selecionada em função da proximidade geográfica do centro de investigação.

\section{RESULTADOS E DISCUSSÃo}

Neste sentido, através da análise da Figura 2, podemos salientar que se verifica uma tendência ideológica, por parte do eleitorado, em se autocolocar na posição 5 do espectro Esquerda-Direita de 10 pontos. A Figura 2 permite-nos constatar que as posições do espectro que apresentam menor percentagem são as posições extremistas, quer de Esquerda quer de Direita, ainda que a posição 10 - em comparação com as posições 1,2 e 9 - seja a que se encontra mais representada, com 3,30\%, demonstrando uma preferência de autocolocação do eleitorado pela Direita.

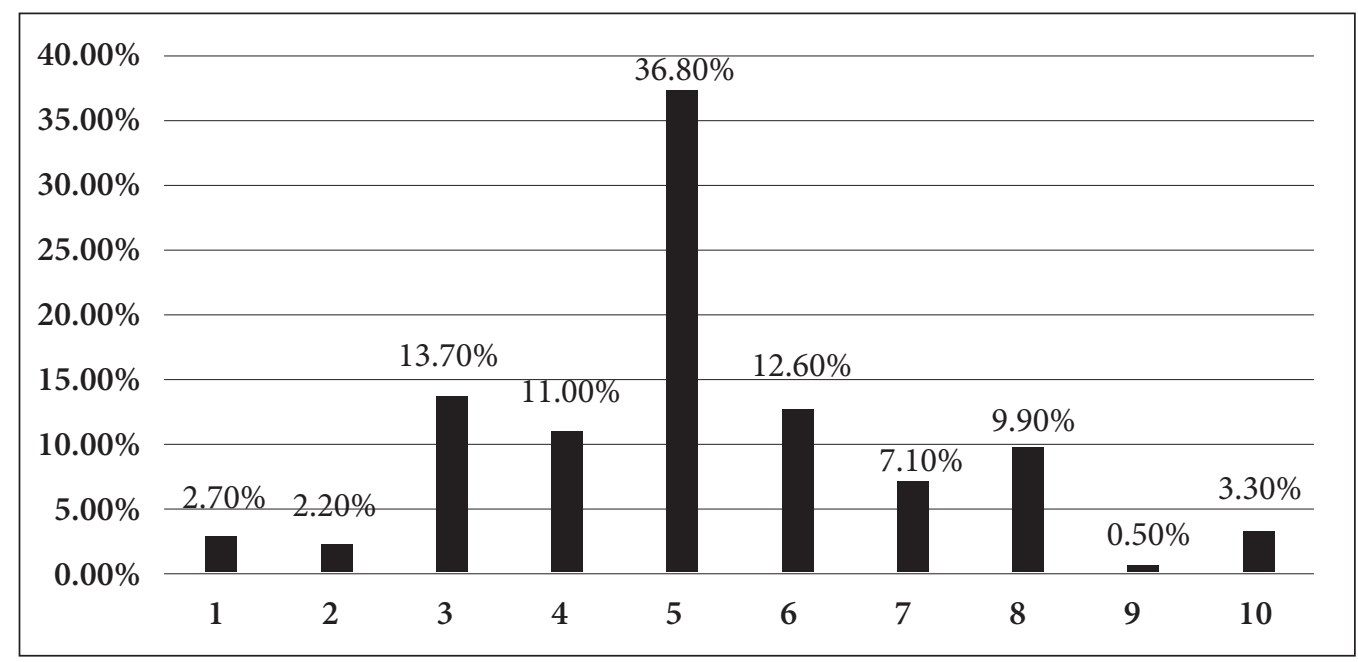

Figura 2. Autocolocação na escala política Esquerda-Direita (1-10).

Esta tendência, pelas posições centristas, vai ao encontro dos resultados obtidos por vários estudos no âmbito do comportamento do eleitorado europeu (Freire, 2006; Klingemann, 1972; Knusten, 1998; Weber, 2012). A este respeito, Freire (2006b, pp. 206-207) apresenta três razões pela escolha consistente do Centro em quase todos os países da Europa Ocidental. Em primeiro lugar, a escolha pelo Centro pode estar 
relacionada, simplesmente, com o facto de os inquiridos acreditarem que as suas ideologias políticas são centristas. Em segundo lugar, essa escolha pode significar a falta de apreço pela política e/ou com o facto do inquirido não se querer comprometer nem com a Direita nem com a Esquerda, apresentando assim uma forma de escapar à questão. Em terceiro lugar, Freire (2006b) vai ao encontro da segunda opção, demonstrando que se deve a "uma certa irrelevância (crescente) da divisão esquerda e direita" (Freire, 2006b, pp. 207), admitindo não ser fácil distingui-las e referindo ainda que "uma boa parte dos centristas são efetivamente indivíduos com menores recursos [...] traduzindo défices de recursos e apatia política" (Freire, 2006b, p. 207).

Contudo, Inglehart e Kligemann (1976), num estudo que envolveu 42 países, demonstram que a autocolocação na escala política Esquerda-Direita encontra-se, intimamente, relacionada com os aspetos sociais, de valor e com as orientações partidárias que constituem as pessoas. Esta última apresenta ser o fator com maior peso na decisão do eleitor em se autocolocar no espectro político Esquerda-Direita (por exemplo, Fuchs \& Klingemann, 1990; Huber, 1989; Inglehart \& Klingemann, 1976), pelo que considerámos fundamental averiguar se o mesmo se aplica ao eleitorado de Vila Real.

Desta forma, a partir da leitura da Tabela 1, denotamos que a orientação partidária dos inquiridos desempenha um papel fundamental na sua autocolocação na escala política Esquerda-Direita. Importa, pois, salientar que as pessoas, que se autoconsideram de Esquerda, pretendem votar nos partidos que se identificam, ideologicamente, com a Esquerda e as pessoas, que se autoconsideram de Direita, pretendem votar nos partidos que se encontram na Direita. O mesmo acredita Freire (2006a), que refere como sendo um efeito demasiado óbvio. A Tabela 1 permite-nos verificar que os partidos políticos relevantes do sistema partidário português abarcariam os votos, em caso de eleições, nas pessoas que se autocolocaram nas mesmas posições, que à partida, os partidos ocupam. No caso do CDS/PP, podemos observar que a maior percentagem de votos se concentra nas pessoas que se autocolocaram na posição 8. Já o BE e o PCP acarretariam maior percentagem de votos nas pessoas que se autocolocaram na posição 2. Relativamente ao PS e PSD, podemos verificar que fica assente a ideia de partidos catch-all (ver Kirchheimer, 1990), uma vez que são os partidos que captam maior percentagem de votos, sendo que, no caso do PS, preferencialmente das pessoas que se autocolocaram no lado da Esquerda do espectro, e no caso do PSD, no lado da Direita do espectro. Estes últimos são os partidos que mais votos teriam das pessoas que se autocolocaram no Centro da escala. Especial destaque ainda 
para os $29 \%$ das pessoas que não responderam à questão sobre em que partido votariam e que, por sinal, dizem respeito a pessoas que se autoconsideram na posição 5, demonstrando uma certa irrelevância quer pela Esquerda quer pela Direita.

Tabela 1

Influência da Orientação Partidária na Autocolocação dos Inquiridos no Espectro Político Esquerda-Direita (0-10).

\begin{tabular}{|c|c|c|c|c|c|c|c|c|c|c|}
\hline & \multicolumn{10}{|c|}{$\begin{array}{l}\text { Escala Política Esquerda-Direita (1-10) } \\
\text { Percentagem de votos de acordo a posição de autocolocação }\end{array}$} \\
\hline & 1 & 2 & 3 & 4 & 5 & 6 & 7 & 8 & 9 & 10 \\
\hline CDS-PP & $0 \%$ & $0 \%$ & $0 \%$ & $6 \%$ & $0 \%$ & $0 \%$ & $8 \%$ & $29 \%$ & $0 \%$ & $17 \%$ \\
\hline PSD & $0 \%$ & $0 \%$ & $0 \%$ & $0 \%$ & $28 \%$ & $50 \%$ & $67 \%$ & $53 \%$ & $100 \%$ & $67 \%$ \\
\hline PS & $60 \%$ & $50 \%$ & $64 \%$ & $72 \%$ & $31 \%$ & $23 \%$ & $17 \%$ & $12 \%$ & $0 \%$ & $17 \%$ \\
\hline BE & $20 \%$ & $25 \%$ & $12 \%$ & $6 \%$ & $6 \%$ & $5 \%$ & $0 \%$ & $0 \%$ & $0 \%$ & $0 \%$ \\
\hline PCP & $0 \%$ & $25 \%$ & $4 \%$ & $0 \%$ & $0 \%$ & $0 \%$ & $0 \%$ & $0 \%$ & $0 \%$ & $0 \%$ \\
\hline Outros & $20 \%$ & $0 \%$ & $8 \%$ & $17 \%$ & $6 \%$ & $5 \%$ & $0 \%$ & $0 \%$ & $0 \%$ & $0 \%$ \\
\hline Não respondeu & $0 \%$ & $0 \%$ & $12 \%$ & $0 \%$ & $29 \%$ & $23 \%$ & $8 \%$ & $6 \%$ & $0 \%$ & $0 \%$ \\
\hline
\end{tabular}

No entanto, pela análise da Figura 3, podemos verificar a posição que o eleitorado do concelho de Vila Real realmente ocupa dentro da dimensão política Esquerda-Direita. O que nos permite verificar, desde logo, que o campo político-ideológico que o define não corresponde com a posição que este acredita ocupar no espectro Esquerda-Direita, representado pela Figura 2. Importa, assim, referir que os dados apresentados, pela Figura 3, dizem respeito ao cálculo das respostas do eleitorado a questões relacionados com aspetos religiosos, morais, socioeconómicos, raciais e sociais, sempre com opção de resposta dentro de uma escala de 10 pontos, na qual 1 está para a Esquerda e 10 para a Direita.

Deste modo, após a análise das respostas dos inquiridos a estas questões, contrariamente àquilo que a maioria pensa, a julgar pelas posições em se autocolocaram, 
verificamos que o eleitorado do concelho de Vila Real ocupa, ideologicamente, o campo atinente ao Centro-Direita, com 35,5\% dos inquiridos posicionados na posição 6. Pela análise da Figura 3, denota-se que o eleitorado em análise pertence ideologicamente ao campo da Direita do espectro, não apenas pela elevada percentagem que a posição 6 representa, mas também pelo o eleitorado que se apresenta como pertencendo à posição 7 .

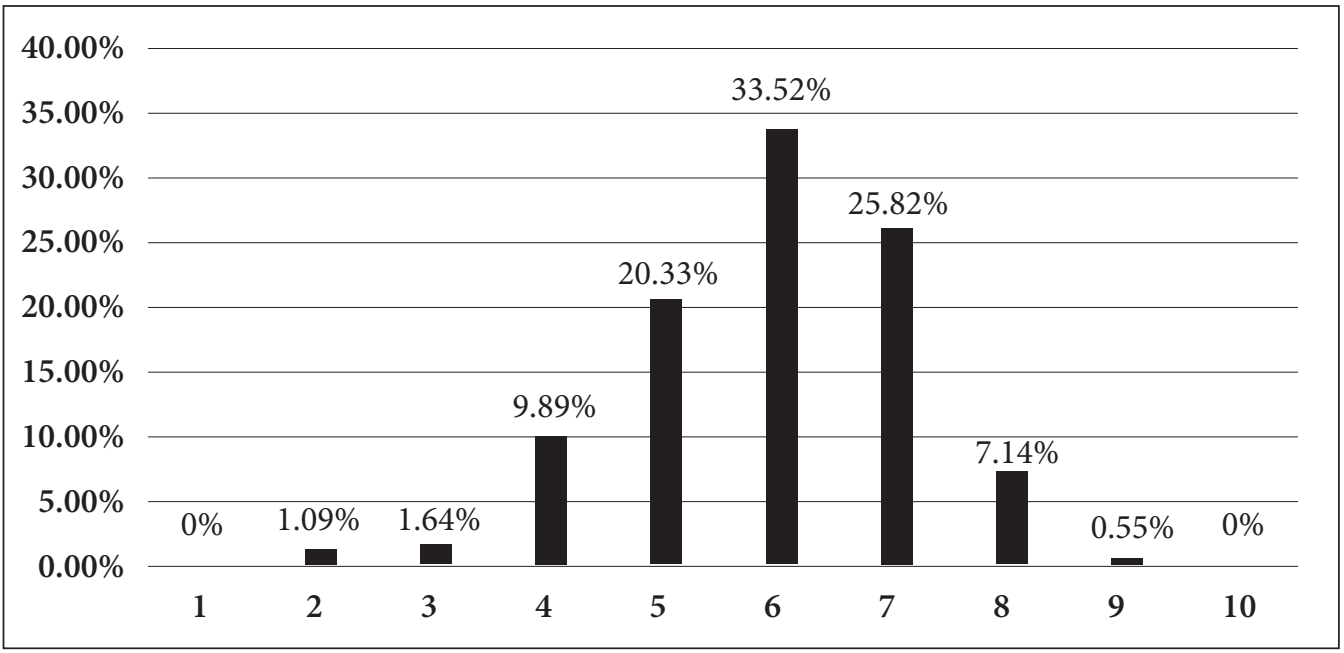

Figura 3. Posição do Eleitorado do Concelho de Vila Real na Escala Política Esquerda-Direita (1-10).

Jacoby (1991) e Converse (2006) acreditam que a maioria dos cidadãos não apresenta um conhecimento profundo da dicotomia política Esquerda-Direita, limitando esse conhecimento apenas às elites políticas. Já Fuchs e Klingemann (1990) acreditam que os termos Esquerda e Direita funcionam como mecanismos de orientação política para os eleitores, no entanto a compreensão desses rótulos ideológicos pode ser bastante reduzida. Relativamente a este aspeto, Freire (2006b, p. 188) demonstrou que nos anos entre 1976 e 2002, Portugal fazia parte dos países com valores mais baixos de identificação ideológica, o mesmo se verifica com a Espanha, o que corrobora a tese de alguns autores (por exemplo, Barnes, Mcdonough, \& Pina, 1985) que acreditam que estes valores são mais baixos nas democracias mais novas, por haverem saído há relativamente pouco tempo de um sistema autoritário. No entanto, 
Freire (2006b) verificou um aumento da habilidade ou capacidade dos eleitores em se autoposicionarem na escala política Esquerda-Direita ao longo dos anos.

Neste contexto, importa acrescentar que o nosso estudo demonstrou uma maior capacidade de autocolocação na escala Esquerda-Direita nos inquiridos pertencentes à faixa etária igual ou superior a 65 anos e que esta capacidade se revelou mais eficaz nos inquiridos que possuem maior grau de formação e/ou académico, como comprova a Figura 4.

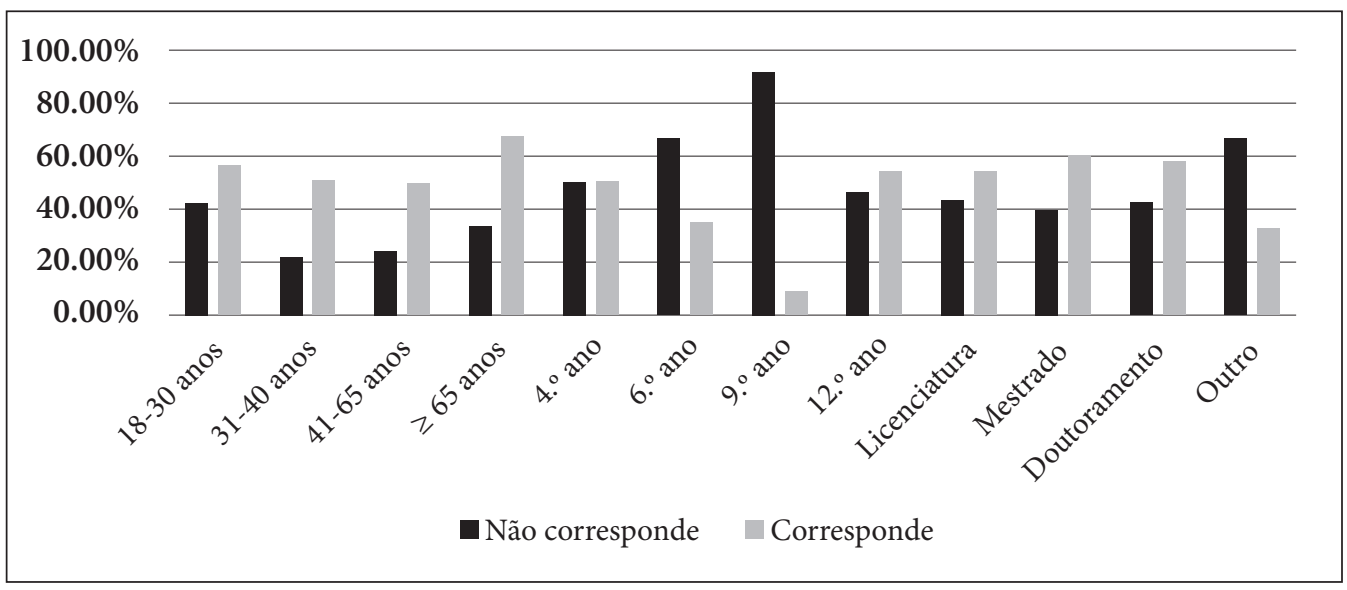

Figura 4. Capacidade de Autocolocação dos Inquiridos de Acordo com a sua Faixa Etária e com as suas Habilitações Literárias.

Sendo assim, os nossos resultados corroboram o pensamento de Fuchs e Klingemann (1990), quando referem que o reconhecimento e a compreensão do espectro político Esquerda-Direita aumentam com o grau da educação, salientando que o compreensão torna-se mais afetada do que, propriamente, o conhecimento, pela formação que o indivíduo possui. No entanto Fuchs e Klingemann (1990) frisam que esta díade política é, amplamente, familiar quer no seio das elites informadas, quer para o público em geral. Já Freire (2006b) refere que é natural haver um maior conhecimento do esquema pela geração mais velha, uma vez que o conhecimento político aumenta à medida que envelhecemos. Porém, isso dever-se-ia verificar nas democracias mais antigas, ao invés de nas democracias mais novas, como Portugal, já que o convívio com esta díade é relativamente recente.

No entanto, a nossa investigação, corroborando essa desconformidade do posicionamento dos inquiridos relativamente à sua autoperceção ideológica, demonstra-nos 
que existe, de facto, por parte deste eleitorado, dificuldade em se autoposicionar na escala política Esquerda-Direita de acordo com os valores que o identificam. Neste sentido, o Figura 5 permite-nos verificar que uma elevada percentagem de inquiridos $(47,25 \%)$ se autocolocou numa posição, dentro da respetiva escala, que não corresponde à posição que as suas respostas ao questionário acusam. Apenas 52,75\% é que se autoposicionou corretamente.

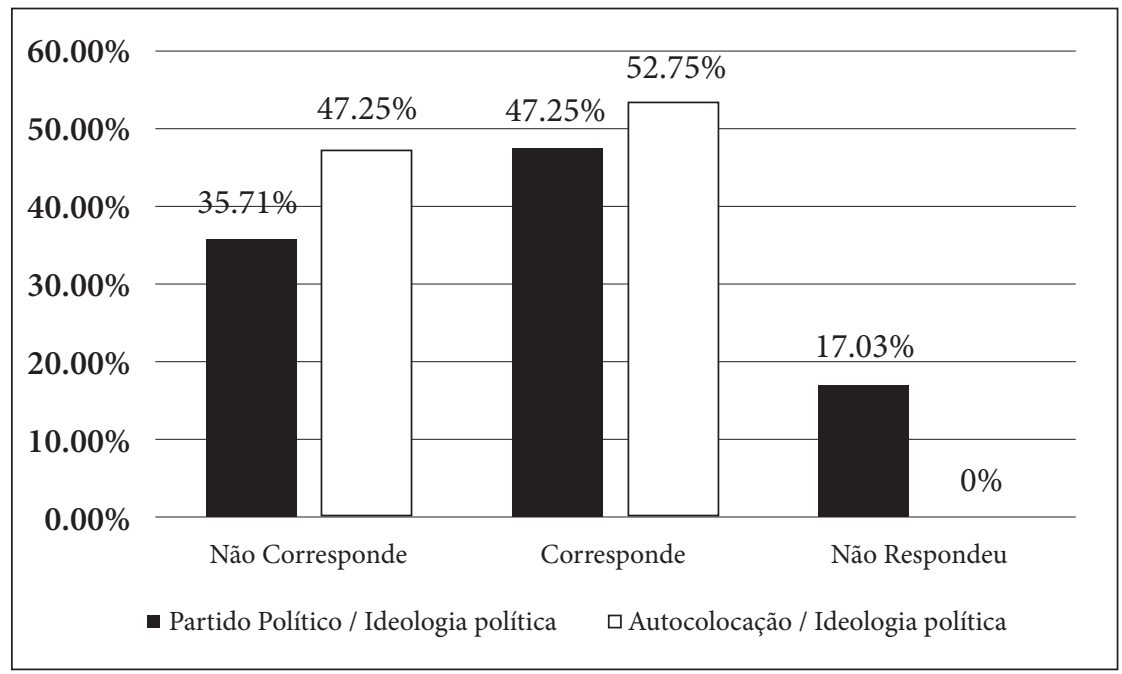

Figura 5. Índice de Correspondência da Ideologia dos Inquiridos Comparativamente à Posição Ideológica dos Partidos em que Votariam e à Posição em que se Autocolocaram na Escala Política Esquerda-Direita.

Já no que diz respeito ao índice de correspondência entre a posição ideológica e o partido político em que, os inquiridos, votariam, em caso de eleições, a falta de conhecimento do espetro político e a dificuldade em nele se autocolocar e identificar torna-se, novamente, saliente, como atesta o Figura 5. Desta forma, apenas 47,25\% dos inquiridos apresenta uma ideologia ou uma posição ideológica que corresponda com o partido em que votariam, demonstrando, assim, alguma inconsciência relativamente às identidades dos partidos. Contudo, importa referir que estes resultados podem significar também alguma volatilidade ideológico-partidária dos mesmos. 


\section{Ideologia Política Esquerda-Direita - Estudo Exploratório do Eleitorado Português}

\section{CONCLUSÃO}

A presente investigação permitiu-nos concluir que, à semelhança dos resultados de outros estudos presentes na literatura, subsiste a tendência de as pessoas se autocolocarem no Centro do Espectro Político, quando questionadas sobre a sua autoperceção ideológica de acordo com a Escala Política Esquerda-Direita. Essa tendência revelou ser fortemente influenciada pela orientação partidária do inquirido, levando-nos a concluir que as pessoas, quando questionadas, recorrem a um exercício de reflexão sobre a posição que ocupa, na respetiva escala, o seu partido político e, só depois, de acordo com esse resultado, é que atribuem uma posição a si próprias.

Sendo o concelho de Vila Real um concelho manifestamente de Direita, a julgar pelos resultados eleitorais ao longo de toda a democracia (vide:http://eleicoes.cne. pt), esta investigação procurou averiguar a que campo político, Esquerda ou Direita, os inquiridos pertencem em termos ideológicos, pelo que, através da análise dos nossos resultados, verificámos que integram, ideologicamente, o campo da Direita, na posição 6 e 7, na escala em que 1 está para a Esquerda e 10 para a Direita. No entanto, revelou-se, ainda, que existe uma tendência para as pessoas se autocolocarem numa posição mais à Esquerda do que aquela que realmente ocupam.

No que diz respeito ao nível de compreensão e de reconhecimento, por parte do eleitorado, da dimensão ideológica Esquerda-Direita, os nossos resultados demonstraram que, ainda que haja um elevado reconhecimento da escala pela maioria dos inquiridos, subsiste uma elevada percentagem de inquiridos que apresenta dificuldades em compreender e reconhecer os vários campos ideológicos, quer da Esquerda, quer da Direita. São os inquiridos mais instruídos ou pertencentes a uma faixa etária mais envelhecida que melhores índices de compreensão da escala apresentam.

Os nossos resultados vão, ainda, ao encontro do que vários estudos têm apresentado como sendo o perfil dos inquiridos de Esquerda e de Direita. À semelhança da literatura, os inquiridos considerados de Direita revelam-se mais religiosos, intolerantes aos imigrantes, a favor da ordem social e mais céticos em relação ao aborto, comparativamente com os de Esquerda. Os inquiridos de Esquerda identificam-se mais, comparativamente aos da Direita, com os novos valores e clivagens, aliadas à nova sociedade não económica e assente nos valores pós-materialistas a favor dos movimentos libertários e ambientais.

Assim sendo, pegando na nossa pergunta de investigação, "Será que o eleitorado se autoposiciona, nesta escala, aquando questionado sobre a sua autoperceção ideo- 
lógica, de acordo com a sua identidade partidária e decisão eleitoral?", verificamos que os inquiridos são fortemente influenciados pela sua orientação partidária para se autoposicionarem na Escala Política Esquerda-Direita, o que reflete elevadas dificuldades em compreender e reconhecer os valores ideológicos da dicotomia Esquerda-Direita.

Em termos teóricos, a díade política Esquerda-Direita continua a fazer sentido no universo político na imensa maioria das democracias ocidentais. Apesar das críticas de que esta díade tem sido alvo ao longo dos anos, alegando a sua falta de capacidade em lidar com os novos temas aliados a um mundo globalizado, a verdade é que serve, diariamente, de mecanismo não apenas de orientação, mas também de linguagem política para todos os envolvidos num mundo civilizado e político.

\section{REFERÊNCIAS}

Achterberg, P. (2006). Class voting in the new political culture: Economic, cultural and environmental voting in 20 western countries. International Sociology, 21(2), 237-261. doi:10.1177/0268580906061378

Aron, R. (1955/1980). O ópio dos intelectuais. Brasília: Editora Universidade de Brasília.

Ball, T., Dagger, R., \& O’Neill, D. (2014). Political ideologies and democratic ideal. $9^{\text {th }}$ edition. United States of America: Pearson Education.

Barnes, S. H., Mcdonough, P., \& Pina, A. L. (1985). The Development of Partisanship in New Democracies: The Case of Spain. American Journal of Political Science, 29(4), 695-720. doi: $10.2307 / 2111177$

Belchior, A. M. (2008). Democracia nos partidos políticos portugueses: uma análise do eleitorado, dos programas e dos estatutos dos partidos. Sociologia, problemas e práticas, 58, 131-153.

Bell, D. $(2015,1960)$. El final de la ideologia. Madrid: Alianza editorial.

Bobbio, N. (1995). Direita e Esquerda: razões e significados de uma distinção política. São Paulo: Editora da Universidade Estadual Paulista. 


\section{Ideologia Política Esquerda-Direita - Estudo Exploratório do Eleitorado Português}

Bresser-Pereira, L. C. (1997). Por um partido democrático de esquerda e contemporâneo. Lua Nova, (39), 53-71.

Budge, I., \& Klingemann, H.-D. (2001). Finally! Comparative over-time mapping of party policy movement. In I. Budge, H-D. Klingemann, A. Volkens, J. Bara, \& E. Tanenbaum (Eds.), Mapping policy preferences. Estimates for parties, electors and governments 1945-1998 (pp. 19-50). New York: Oxford University Press.

Burke, E. (1982). Reflexões sobre a revolução em França. Brasília: Editora Universidade de Brasília.

Converse, P. E. (2006). The nature of belief systems in mass publics (1964). Critical Review, 18(1-3), 1-74. doi:10.1080/08913810608443650

Correia, V. (2012). Introdução. A dicotomia política esquerda-direita: a problemática da sua validade e actualidade. Lisboa: Fonte da Palavra.

Currito, E. (2012). Repensar a dicotomia direita-esquerda. A dicotomia política esquerda-direita: a problemática da sua validade e actualidade. Lisboa: Fonte da Palavra.

Dalton, R. (2010). Ideology, partisanship, and democratic development. In L. LeDuc, R. G. Niemi, \& P. Norris (Eds.), Comparing Democracies: Elections and Voting in the 21st Century (pp. 143-164). London: SAGE Publications Ltd. doi: $\underline{10.4135 / 9781446288740 . n 7}$

Duarte, M. (2016). Recensão [Recensão do livro As direitas na democracia Portuguesa: Origens, percursos, mudanças e novos desafios, por R. Marchi]. Sociologia, Problemas e Praticas, 81, 213-217.

Eatwell, R. (1992). Part I: Approaching the Right. The Nature of the Right. American and European Political Thought Since 1789 (pp. 1-78). Londres: Pinter.

European Values Study [EVS] (2016), European Values Study 2008: Integrated Dataset (EVS 2008). GESIS Data Archive, Cologne. ZA4800 Data file Version 4.0.0.

Eysenck, H. (1964). Sense and nonsense in psychology. Harmondsworth: Penguin.

Flanagan, S. (1987). Value change in industrial societies. American Political Science Review, 81(4), 1303-1319. 
Flanagan, S., \& Lee, A. R. (2003). The new politics, culture wars, and the authoritarian-libertarian value change in advanced industrial democracies. Comparative Political Studies, 36(3), 235-270.

Freire, A. (2005). Identidades ideológicas e partidárias na Europa: Portugal, Espanha e Grécia em perspectiva comparativa. Sociologia, Problemas e Práticas, 47, 11-33.

Freire, A. (2006a). Bringing social identities back in: The social anchors of left-right orientation in Western Europe. International Political Science Review, 27(4), 359-378. doi:10.1177/0192512106067358

Freire, A. (2006b). Esquerda e direita na política europeia: Portugal, Espanha e Grécia em perspetiva comparada. Lisboa: Imprensa de Ciências Sociais (ICS).

Freire, A. (2009). A esquerda europeia ante os dilemas da imigração. Sociologia,19, 255-279.

Fuchs, D. \& Klingemann, H.-D. (1990). The left-right schema. In M. K. Jennings \& J. Van Deth (Eds.), Continuities in political action (pp. 203-34). Berlin: Gruyter.

Fukuyama, F. (1989). The end of history? The National Interest, (16), 3-18. Retrieved from http://www.jstor.org/stable/24027184

Gall, C., \& Magni-Berton, R. (2013). Left-Right vs. traditional and new cleavages: Testing durability of an old political category. Left and Right: The Great Dichotomy Revisited (pp. 255-268). Cambridge: Cambridge Scholars Publishing.

Giddens, A. (1995). Para além da esquerda e da direita. O futuro da política radical. São Paulo: Editora da Universidade Estadual Paulista.

Guedes, N. (2012). Convergência ideológica e de políticas públicas? (Tese de Doutoramento, ISCTE-IUL). Retrieved from https://repositorio.iscte-iul.pt/hand$\underline{\text { le/10071/6726 }}$

Heywood, A. (2003). Political ideologies: An introduction. Basingstoke: Palgrave Macmillan.

Huber, J. (1989). Values and partisanship in left-right orientations: Measuring ideology. European Journal of Political Research, 17, 599-621. 


\section{Ideologia Política Esquerda-Direita - Estudo Exploratório do Eleitorado Português}

Huber, J., \& Inglehart, R. (1995). Expert interpretations of party space and party locations in 42 societies. Party politics, 1(1), 73-111.

Inglehart, R. (1971).The silent revolution in Europe: intergenerational change in postindustrial societies. American Political Science Review, 65(4), 991-1017.

Inglehart, R. (1990). Culture shift in advanced industrial society. Princeton, NJ: Princeton University Press.

Inglehart, R. (1997). Modernización y posmodernización: El cambio cultural, económico y político en 43 sociedades. Madrid: Siglo XXI (CIS).

Inglehart, R., \& Klingemann, H.-K. (1976). Party identification, ideological preference and the left-right dimension among western mass publics. In I. Budge, I. Crewe, \& D. Farlie (Eds.), Party identification and beyond: Representations of voting and party competition (pp. 243-273). London: Wiley.

Ignazi, P. (1992). The silent counter-revolution. Hypotheses on the emergence of extreme right-wing parties in Europe. European Journal of Political Research, 22, 3-34.

Jacoby, W. (1991). Ideological identification and issue attitudes. American Journal of Political Science, 35(1), 178-205.

Jost, J., Federico, C., \& Napier, J. (2009). Political ideology: Its structure, functions, and elective affinities. Annual review of psychology, 60, 307-337.

Kirchheimer, O. (1990). The catch-all party. In P. Mair (Ed.), The West European Party System (pp. 50-60). Oxford: Oxford University Press.

Kistchelt, H. (1988). Left-libertarian parties: Explaining innovation in competitive party systems. World Politics, 40(2), 194-234.

Kitschelt, H., \& Hellemans, S. (1990). The left-right semantics and the new politics cleavage. Comparative Political Studies, 23(2), 210-238.

Klingemann, H. (1972). Testing the left-right continuum on a sample of German voters. Comparative Political Studies, 5(1), 93-106.

Knutsen, O. (1995). Value orientations political conflicts and left-right identification - a comparative study. European Journal of Political Research, (28), 63-93. 
Knutsen, O. (1998). Europeans move towards the center: A comparative longitudinal study of left-right self-placement in Western Europe. International Journal of Public Opinion Research, 10(4), 292-316. doi:10.1093/ijpor/10.4.292

Kroh, M. (2005). Surveying the left-right dimension: The choice of a response format. DIW Berlin, German Institute for Economic Research, 491, 1-12.

Lachat, R. (2015). Which way from left to right? The issue basis of citizens' ideological self-placement in Western Europe. Universitat Pompeu Fabra.

Laponce, J. (1981). Left and Right: The Topography of Political Perceptions. Toronto: University of Toronto Press.

Lipset, S. (1987). ¿El fin de toda ideología? e Un concepto y su historia: el fin de la ideología. El Hombre Político: Las Bases Sociales de la Política (pp. 357-372 e 420448). Madrid: Editorial Tecnos.

Lisi, M. (2010). Moderados, pragmáticos e personalizados. A evolução dos partidos de esquerda na Europa do Sul. Sociologia, Problemas e Práticas, 64, 59-80.

Luhmann, N. (1981). Der politische Code: "Konservativ" und "Progressiv" in sytemtheoretischer Sicht. Soziologische Aufklärung 3. Opladen: Westdeutscher Verlag

Lukes, S. (2003). Epilogue: the grand dichotomy of the twentieth century. In T. Ball \& R. Bellamy (Eds.), The Cambridge history of twentieth century political thought. Cambridge: CUP

Pinto, J. (1996). A direita e as direitas. Lisboa: Difel.

Rosas, J. C., \& Ferreira, A. R. (2013). Left and right: Critical junctures. In J. C. Rosas \& A. R. Ferreira (Eds.), Left and right: The great dichotomy revisited (pp. 2-20). Newcastle: Cambridge Scholars Publishing.

Rothbard, M. (2010). Esquerda e direita: Perspectivas para a liberdade. São Paulo: Instituto Ludwig von Mises Brasil.

Tavares, R. (2015). Esquerda e Direita guia histórico para o século XXI. Lisboa: Tinta-da-china. 
Ideologia Política Esquerda-Direita - Estudo Exploratório do Eleitorado Português

Weber, W. (2012) Behind left and right. The meaning of left-right orientation in Europe (Tesi Doctoral, Universitat Pompeu Fabra). Retrieved from https://www.tdx.cat/ bitstream/handle/10803/107624/tww.pdf? sequence $=1$

Weisberg, H. (1974). Dimensionland: An excursion into spaces. American Journal of Political Science, 18(4), 743-776.

Wittgenstein, L. (2010). Philosophical investigations. Chicester: John Wiley and Sons Ltd. 